Original Research Report

\title{
Dynamics surrounding the Implementation of the Primary Health Care Approach in Zimbabwe's Rural Areas: The Case of Mt Darwin District
}

\author{
Sharon R. T. Muzvidziwa-Chilunjika ${ }^{1}$, Alouis Chilunjika ${ }^{2}$ \\ ${ }^{1}$ Department of Politics and Public Management, Midlands State University. PO BOX \\ 100, Buchwa Road. Zvishavane, Zimbabwe. \\ ${ }^{2}$ School of Public Management, Governance and Public Policy, University of \\ Johannesburg. PO BOX 524, Auckland Park. Johannesburg, South Africa.
}

Article History
Received:
17.10 .2020
Revised:
20.11 .2020
Accepted:
23.12 .2020
*Corresponding Author:
Sharon R.T. Muzvidziwa-
Chilunjika
Email:
srtchilu@gmail.com

This is an open access article, licensed under: $\mathrm{CC}-\mathrm{BY}-\mathrm{SA}$
Abstract: This research studied the implementation of the Primary Health Care approach to health service delivery in Zimbabwe's rural areas from 2009 to 2012. The approach was launched in response to the Alma-Alta Declaration in 1978 which sought to end the inequalities in health care provision around the globe and was first adopted and implemented in 1982 in Zimbabwe. The approach almost collapsed due to the economic meltdown in the past decade but the period 2009 to 2013 marked a new economic paradigm in Zimbabwe which saw the economy being dollarized which subsequently led to the revival and the resuscitation of the health sector. It is therefore to explore the progress and the dynamics surrounding the implementation of the PHC at Mt Darwin Hospital in light of the dollarized economy. The study explores the dynamics surrounding the implementation of PHC at Mt Darwin District Hospital by particular attention to the following key elements: promotion of nutrition, sanitation, maternal and child care, immunization, treatment of common diseases and provision of essential drugs. Qualitative techniques such as face to face interviews with key informants and documentary research were used to generate data. The research findings revealed that $\mathrm{PHC}$ is a powerful tool in delivering health services in Mt Darwin. However, lack of material, financial and human resources have hindered the proper implementation of the PHC approach in Mt Darwin district. The study recommends multi sectoral collaboration in solving health related issues.

Keywords: Accessibility, Affordability, Health Service Delivery, Implementation, Primary Health Care. 
Sharon R.T. Muzvidziwa-Chilunjika, Alouis Chilunjika.

Dynamics surrounding the Implementation of the Primary Health Care Approach in Zimbabwe's Rural Areas: The Case of Mt Darwin District.

International Journal of Clinical Inventions and Medical Sciences, vol. 3, no. 1, pp. 1-17, March 2021. DOI: 10.36079/lamintang.ijcims-0301.162

\section{Introduction}

After realizing the gross inequalities in health services delivery, there was an urgent call for all nations to come together and strategise on ways to improve global health. The Declaration of AlmaAta as noted by Hixon and Maskarine [1] emerged within a historical era characterized both by hope and prospect and by geopolitics of the ongoing cold war. International development economists were pushing for a "New International Economic Order" to address the economic imbalances between developing and developed countries. In response to the calls made by development economists an International Conference on primary health care was held in Alma-Ata a town of the former Soviet Union, new Kazakhstan in 1978 which helped reshape the arenas of public health.

According to the Alma-Ata Declaration [2], Primary health care (PHC) is essential health care based on realistic, scientifically, sound, and generally acceptable methods and technology made unanimously accessible to individuals and families in the society through their full involvement at a cost that the society and the nation can afford to uphold at every stage of their development in the spirit of independence and self-determination.

The Declaration called for pressing and effective state and global action to build up and implement primary health care all over the world to address the gross inequalities in the health status of the people. In Zimbabwe, the programme was launched in 1982 in response to this call. Programmes such as hospital rural health care building, Zimbabwe's expanded programme on immunization, diarrheoral disease-control and National nutrition programme as argued by Sanders [34] were introduced by the government in the 1980s response to the Declaration. Accordingly Kazembe [4] argued that the Zimbabwe health sector was decentralized and democratized in a significant measure during the first decade of policy making as the Primary Health Care programme was centered on providing basic preventive, promotive, curative and rehabilitative interventions in rural areas. The government of Zimbabwe adopted the Primary Health Care (PHC) approach, as suggested by Sunanda \& Masuka [5] directing resources towards disadvantaged areas and active participation of communities in transforming their health. National health strategies have continued to endorse the PHC approach as underpinning health provision, but skills migration, low investment and limited resources have deterred this ambition.

Mlambo \& Raftopoulos [6] noted that in the past decade or so Zimbabwe has been in a severe crisis which has seen a once lively and vibrant society failing due to political insecurity, chaos, misgovernment and economic meltdown. The World Bank Report [7] stated that, Zimbabwe had the world's fastest shrinking economy for a country not at war. Against this background, Reuters argued that the social services such as health, clean water supply and sanitation crumbled leading to the decline of life expectancy rates of 63 years in 1990 to 40.9 in 2005. Additionally, Reuters asserts that, HIV and AIDS infections rose as well with an average death rate of 3200 people per week in 2007 making Zimbabwe the fourth highest HIV and AIDS prevalent country in the world. It should be noted the once widely admired Primary Health Care system quickly declined as drug and staff shortages meant that no meaningful health care could be provided in most hospitals and clinics which had been built in the 1980s. In light of this, Sunanda \& Masuka [5] argued that following impressive health gains in the first decade following independence in 1980, the health sector in Zimbabwe has been severely undermined by the human immunodeficiency virus (HIV) epidemic and economic crises, which worsened from the mid-1990s.

In 2009 Zimbabwe welcomed a new era as the two major political parties Zanu PF and MDC established a Government of National Unity in an effort to politically and economically stabilize the country. The Reserve Bank of Zimbabwe also approved the official use of a multi-currency system of five foreign currencies which allows trade in foreign currency resulting in economic and political stability. Given such a scenario, Kanyenze [8] argued that the multi-currency system paved way for the dollarization of the economy which saw a revival in the economic affairs of the nation. All the sectors of the country witnessed some remarkable improvement in their capacity and operations. There was the implementation of the Health Plans and other supporting health related initiatives. The 100 day Health Action Plan, implemented from March to June 2009 was specifically aimed at getting the health care system functioning again towards the attainment of Millennium Development Goals which include the eradication of extreme poverty and hunger, reduction of maternal and child mortality and to combat the spread of HIV/AIDS, Malaria and TB by strengthening primary health care systems. 
Despite the efforts by the government to decentralize health care, most rural areas still lack quality health care, due to poor communication and transport systems, shortages of drugs, poor equipment, health infrastructure and lack of senior experienced staff and information technology equipment to enhance their professional growth. Those admitted at rural hospitals also lack balanced meals as there are no funds to purchase foodstuffs. The Ministry of Health and Child Welfare adopted the National Health Strategy of 2009-2013 "Equity and Quality in Health: A People's Right" which provides a framework for the resuscitation of the health sector using the Primary Health Care Approach. In this vein, Sunanda \& Masuka [5] noted that the implementation of health strategies such as the Primary Health Care (PHC) Approach in the urban areas improved remarkably during this period. Accordingly Sunanda \& Masuka [5] contended that the near collapse of the health system in 2008 was followed in 2009-2012 by some recovery of the economy and renewed investment in health services. As such, it is against this background that this study assesses how this strategy is implementing the Primary

Health Care Approach in ensuring equity and quality in Zimbabwean rural areas during this period of significant economic turnaround. The thrust being to gauge if the improvements in health provision using decentralized models such as PHCs had the same effects in the rural areas as was the case with urban areas.

There is concern over poor health service delivery in Mt Darwin which is characterized by high maternal and child mortality, drug shortages, lack of senior staff and information technology equipment to deliver quality health care. Mt Darwin has a high incidence of Malaria and HIV/AIDS hence worsening the prevalence of health problems. The study questions the extent to which the Primary Health Care Approach provides the best tool for providing quality health care with particular reference to rural areas.

\section{Literature Review}

\subsection{Primary Health Care}

2.1.1. Definition of Primary Health Care

Firstly, it is important to define Primary Health Care (PHC) according to various scholars as it is central to this study. Primary Health Care (PHC) is a conceptual model which refers to both processes and values about the ways in which health care is prearranged. PHC as indicated by Shoultz \& Hatcher [9] encompasses primary care, sickness prevention, health promotion, public health, and community development within a holistic framework, with the aim of providing critical peoplefocused health care. Moving on, The Institute of Medicine [10] describes PHC as the provision of integrated, accessible health care services by professionals who are liable for addressing a number of personal health care needs, developing a continuous relationship with patients, and practicing in the context of family and society. Deriving a general definition from the above definitions one may define PHC as a system of health service delivery that is available, accessible, acceptable and affordable, maintained through community participation and multisectoral collaboration. Therefore as highlighted by the World Health Organisation [11] the pillars of PHC are access, equity, essentiality, appropriate technology, multisectoral collaboration, and community participation and empowerment.

According to Health Organisation [12] report globalization is putting the social solidity of many nations under stress and health systems as key constituents of the design of contemporary societies are clearly not performing as well as they could and as they should. The only solution to improved health systems is therefore Primary Health Care as it is fast and responsive to the needs of the people. The Zimbabwean National Health Strategy of 2009-2013 says that the Primary Health Care Approach will steer the country towards attainment of Millennium Development Goals which were adopted in 2004 which represent human needs and basic rights that every individual around the world should be able to enjoy freedom from extreme poverty, hunger good health and shelter. Primary health care research as argued by MacLean et.al [13] therefore seeks to appreciate the influence of the socioeconomic, physical, biologic and cultural elements of health within the relevant broader political, socio-historical and economic contexts which will implicate social change.

Primary health care (PHC) is essential health care made universally accessible to individuals and acceptable to them, through full participation and at a cost the community and country can afford. Accordingly, Mona [14] argues that PHC is an approach to health beyond the traditional health care system that focuses on health equity-producing social policy [34]. PHC is the healthcare provided in the community for people making an initial approach to a medical practitioner or clinic for advice or treatment. The Alma Ata conference has put forward eight important aspects of primary health care. 
These are: health education, adequate of safe drinking water, nutrition, immunization, provision of essential drugs, availability and distribution of medicine, treatment of communicable diseases.

The public PHC workforce as highlighted by Loewenson [15] is largely nurse-led, with PHC nurses in rural clinics and nurses, midwives and clinical officers in urban municipality clinics, hospital outpatients and inpatients. Nurse-anesthetists provide the majority of anesthesia in urban and rural hospitals, where caesarean sections are the main surgical procedures. Accordingly, the Ministry of Health and Child Care [16] noted that doctors in public PHC provide supervision and teaching, develop guidelines and consult on referred cases. Nearly every district has at least two medical officers, every PHC center has at least two qualified nurses. 59\% of administrative wards have an environmental health technician and $60 \%$ of villages have access to a village health worker.

Accordingly, the Zimbabwe National Statistics Agency [17] citing the Zimbabwean Constitution noted that the Supreme law of the land recognizes the right of every citizen to primary health care through the right to basic health care services including reproductive health care and requires the State to take reasonable measures within its available resources to progressively guarantee that right. These basic or district core health services are primary health care services and are set out under the Essential Health Benefits Package a prioritized set of services including maternal health, child health, communicable and non-communicable diseases.

According to Ministry of Health and Child Care [18], the basic package of core health services for the primary care level is composed of maternal health care, adolescent sexual and reproductive health services, family planning including prevention of parent-to child transmission (PPTCT) of HIV services, antenatal care including PPTCT of HIV services, delivery care including emergency obstetric and newborn care services, postpartum care including PPTCT of HIV services Noncommunicable disease control, eye conditions, ear, nose and throat conditions, mental health, injuries, accidents and emergencies, diabetes, hypertension and cardio-vascular diseases, common cancers, chronic obstruction respiratory diseases, acute and chronic renal disease Child health care, neonatal care, immunization, integrated management of neonatal and childhood illnesses, newborns and young infant services, essential nutrition package, growth monitoring and promotion, disability services, diarrhea, pediatric HIV Communicable disease control, HIV/AIDS and sexually transmitted infections, tuberculosis, malaria, diarrhoeal diseases.

African conditions and circumstances as argued by Mona [14] present specific challenges to health service providers. These conditions have implications for primary health care (PHC), including problems of communication, geographical, educational and cultural, maldistribution of health manpower, political unrest and wars.

\subsubsection{Health Needs and Problems of Rural Populations}

There is great concern over poor health service delivery in Zimbabwean rural areas which is characterized by high maternal and child mortality, drug shortages, lack of senior staff and information technology equipment to deliver quality health care. Accordingly Peters, Bloom, Walker, Brieger \& Rahman [19] noted that people in rural areas tend to have less access to health services than those in better off areas, and when health care is needed but delayed or not obtained people's health worsens, which in turn leads to lost income and higher health care costs, both of which contribute to poverty.

There are several problems within primary health care delivery system which affect the whole population. According to Abdulrahem, Olapipo \& Almodu [20] an assessment of these problems and needs is important to assure easy accessibility to health care services by rural people. The health and health-related problems of rural people include the following:

Poverty associated with poor housing, poor sanitation, polluted water and food which influence malnutrition and infectious diseases. Accordingly, Murisa [21] asserted that the Department of Nutrition in the Ministry of Health and Child Welfare has never gained prominence compared to other departments in the same ministry. It has remained small with limited personnel, budget and outreach capacity.

As a result, nutrition promotion activities have remained marginalized especially in rural areas:

i. Uneven allocation of health services, and shortage of doctors, nurses and trained health workforce in rural areas, vacancy levels stand at 80 percent midwives, 62 percent nursing tutors and over 50 percent radiology, pharmacy and laboratory personnel [21]. 
Sharon R.T. Muzvidziwa-Chilunjika, Alouis Chilunjika.

Dynamics surrounding the Implementation of the Primary Health Care Approach in Zimbabwe's Rural Areas: The Case of Mt Darwin District.

International Journal of Clinical Inventions and Medical Sciences, vol. 3, no. 1, pp. 1-17, March 2021. DOI: 10.36079/lamintang.ijcims-0301.162

ii. High mortality and low life expectancy, due to lack of access to health services under -five mortality rose from 53 percent to 77 per 1000 live births in 1994 to 67 and 94 per 1000 live births respectively in 2009 [21].

It should be noted that public health goals at all levels of government are influenced by demographic and background variables. In view of this, information about community felt needs becomes vital. These needs should be properly evaluated and coordinated with different sectors and incorporated into existing PHC services for better health service delivery [20]. Mt Darwin, for example has, a high incidence of Malaria and HIV/AIDS and for primary health care to be effective programs to combat these disease should be given first priority.

\subsection{Accessibility, Community Participation and Involvement}

Peters et al. [19] assert that there are numerous definitions of access to health services, with the majority researchers agreeing that access has to do with the timely exploit of services according to need. Accessibility in health service delivery has to do with geographic accessibility. Accordingly, Obioha \& Molale [22] posit that his is the physical distance that one travels to access health services it should be noted that PHC was introduced to be the primary contact level to lighten the challenges of inaccessibility to health care products and services as it is reachable to every person because it is found in communities and also because it is easy to get assistance even during odd hours. Accessible health care is therefore of great importance as it helps promote allocative efficiency and equitable distribution of health services in communities resulting in improved socio-economic standards and living conditions. Accessibility as highlighted by the WHO also entails access to information about health hazards and information important for policy making by relevant actors in the health field [12]. As such PHC facilities should thus be accessible to the patients.

It is almost commonly recognized by national and global health planners that community participation is the answer to the successful implementation of primary health care (PHC). The Declaration of Alma-Ata 1978 as noted by the WHO acknowledged community participation as a process by which individuals and families assume liability for their own health and wellbeing and for those of the community [11]. In Zimbabwe community participation has been institutionalized through the creation of village development committees (VIDCOs) and ward development communities (WADCOs) that are grass-roots organisations expected to work closely with local governments to develop their communities however there is great need for them to support and monitor primary health care implementation.

Citizens or the community as indicated Zimbabwe Health Matters should take responsibility for their own health by taking initiatives in building toilets, gardening projects and attending community health campaigns which educate them on preventing common local diseases which include bilharzia, malaria, diarrhoea and sexually transmitted diseases including AIDS [18]. Similarly, Mike [23] notes that there is a large and growing body of evidence that certain types of service delivery are enhanced with the active participation of the communities they serve.

Promoting community participation as indicated by Abduralrahem et al. [20] is an expertise which must be taught to community health employees, and backed up with support services. They further stipulate that for successful community participation, projects undertaken should be ones that the public would have identified as a priority. Mike [23] noted that the involvement of the public in defining problems, planning, execution and evaluation of the public resources makes them feel accountable, not only for their own health, but also that of others thus improving the standards of their lives. In this regard, Obioha \& Molale [22] state that without the people there would be no Primary Health Care and without Primary Health Care, the society will experience health problems.

\subsection{Collaboration and Partnership with Other Agencies}

The Alma- Ata Declaration states that in addition to the health sector, other related sectors and aspects of national and societal development, in particular agriculture, animal husbandry, food, industry, education, housing, public works, communications and other sectors should co-ordinate in the implementation of the PHC approach. Hegazy et al. [24] argue that no aspects involved in socioeconomic development, especially the health sector, can function properly in isolation hence partnerships are needed to improve health service delivery. For example, the health sector has continued to play its role in the promotion of safe water supply and sanitation facilities and has 
closely with the Ministry of water the safety of drinking water. The 2009-2013 Zimbabwe National Health Strategy emphasize the need for wider social participation of all sectors, communities and individuals however to make intersectoral coordination a reality, intensive efforts should be made to exhibit how ill health and disease are closely related to illiteracy, poverty, poor sanitation and environmental conditions, etc.

\subsection{Functions of Primary Health Care Centers}

All primary health care centers should function in line with the seven aspects of PHC that were stated in Alma- Alta which mainly are teaching about existing health problems and ways of preventing and controlling them; the promotion of food supply and appropriate nutrition; enough provision of safe water and basic sanitation; maternal and infant health care; including family planning and care of high risk groups; immunization against the major contagious diseases; prevention of locally common illness and finally, the provision of vital drugs. However it should be noted though PHC has got seven components, it has not been feasible for developing nations such as Zimbabwe, Kenya and Nigeria to deliver them all equally.

Education about prevailing diseases if found to be functional in most PHC centers. This means that people through the education they acquire can now control and prevent diseases. Furthermore, the promotion of food supply and proper nutrition is functional though to a minimal level in developing countries. This has resulted from severe droughts in most African countries leading to an increase of rural dwellers who are in desperate need to be supplied with food. According to the World Bank, World Development Indicators [7], more than $75 \%$ of populations in sub -Saharan Africa [31] live below the internationally set poverty line of US D 2 per day which means that most Africans cannot afford proper nutrition.

Primary health care centers should also offer maternal and child care services; this is done by teaching mothers to take care of themselves during and after pregnancies. However despite the efforts made at local levels to combat maternal and infant mortality, World Health Organization reports state that maternal mortality rate is highest in the African region, estimated at an average of 1000 deaths per 100,000 live births. This is so due to shortage of resources such as supply of medical facilities (pills, injections and skilled staff) and also due to religious beliefs. As noted by Obioha \& Molale [22] the prevention and control of locally common endemic disease is the linchpin of PHC. Without such services there would be no PHC, hence equipping the community with the knowledge to prevent locally common diseases will prevent them from being infected.

\section{Methodological Framework}

This article focuses on the implementation of the Primary Health Care Approach in a bid to understand health service delivery in rural areas. Guiding the research is the assumption that effective implementation of the Primary Health Care Approach enhances health service delivery in Zimbabwe's rural areas with the Mt Darwin District being the case study. The researchers chose Mt Darwin District Hospital because it is one of the very first rural medical facilities to bankroll the PHC programme and initiative. Accordingly, this place -the Mount Darwin District, lies in the Mashonaland Central Province in north-eastern Zimbabwe. It is located approximately 160 kilometres, by road, northeast of Harare, the capital and largest city in that country [17]. Accordingly, the Zimbabwe National Statistics Agency the 2012 census established that there are 212725 people in Mt Darwin that is 103203 males and 109522 females. In addition, 212309 people stay in the rural areas whilst 416 stay in the urban part of the district, thus making rural side of the case study the focal point of the study. The basic economy of the Mt Darwin District as highlighted by the Zimbabwe National Statistics Agency [17] is communal and subsistence farming and a bit of artisanal gold mining.

The paper revolved around the functions of PHC centres, the implementation of the approach in rural areas and challenges encountered at these centers. This is in essence captured by following questions: What is the rationale of the Primary Health Care approach in rural areas? Is primary health care an effective tool for providing quality health in Mt Darwin? What are the major challenges militating against the effective implementation of Primary Health Care in Mt Darwin? Data collection thus combined documentary review and fieldwork.

Research methodology or research design is defined by Howitt \& Cramer [25] as a plan or blueprint of how a researcher intends to conduct a study. The researchers used qualitative methods of 
gathering data and information. In selecting the respondents, the researchers laid down the criteria for the respondents to be included in the sample, therefore, whoever meets that criteria was be selected in the sample. Thus the researchers employed purposive sampling as a method for selecting the key respondents. Castillo [26] defined purposive sampling as a non-probability sampling technique where the researcher selects units to be sampled based on their knowledge and professional judgement. The researchers had prior knowledge about the respondents as they were users and beneficiaries as well as experts or specialists in the PHC field in Mt Darwin.

The population of the study included twelve members of Mt Darwin community who are the recipients of Primary Health Care who were drawn from Dotito, Mutungagore and Tsakare communal areas, most respondents were females as they tend to use health care services more than males in Mt Darwin. Four of the respondents were village health workers (VHWs) as they are involved in the dayto-day running of the approach, and also they possess the knowledge of how communities utilize the services. These VHWs were drawn from the growth point where the Mt Darwin District hospital is located and they serve the people in the communal areas. Two other respondents were Primary care nurses as they work closer to the village health workers and are the middlemen between the VHWs and the district hospital. The other two were the District Nursing Officer and the District Medical Officer of Mt Darwin Hospital because of their knowledge to primary health care approach. Over and above it can be noted that most of the respondents are resident in the growth point as well as some neighbouring communal areas as Mt Darwin District is a growth point that is surrounded by communal areas (Dotito, Mutungagore and Tsakare).

Desk research was used; this saw an extensive review of academic books, journals, Ministry of Health and Child Care publications, Zimbabwe Statistical Reports and bulletins as well as newspaper articles being conducted to get an insight on the implementation of the PHC approach. The researchers conducted interviews with the above mentioned key informants to gather data on the implementation and usefulness of the approach. The researchers selected Mt Darwin as the case study because it is one of the very first rural areas to successfully implement the PHC initiatives. Using this as the study's focal point enabled the researchers to gauge the success of this ground breaking programme in Mt Darwin.

However, the researchers faced difficulties in getting statistical data especially that of the year 2009 as most health facilities in the district were not functioning well due to the economic meltdown of 2007-2008. The researchers managed to travel with the district's Expanded Programme of Immunization (EPI) team during its January 2015 outreaches however could not reach all the points to interview VHWs and community members due to bad roads as a result of the rainy season, to those points reached other community members lacked full cooperation as they were rushing to go back to their fields.

\section{Presentation and Analysis of Research Findings}

\subsection{The Rationale for the PHC Approach in Rural Areas}

The respondents generally agreed that PHC plays an important role in decentralizing health care services as it is intended to ensure health care coverage at community level through the participation of the people in improving their day-to-day healthy living. Zimbabwe's health system has retained numerous of the structures from its establishment in the early 1980s, although recent attrition of health personnel and limited finances for supporting health operations has narrowed the capacity of the decentralized structures. The activities of Primary Health Care in Mt Darwin are guided by the declaration of Alma-Ata of 1978 [27] which asserts that the programmes should be based on practical, sound and socially acceptable methods accessible to all people.

The District Nursing Officer (DNO) noted that (Primary Health Care) PHC is basic health care which is pro-active rather than reactive as its major goal is to prevent illness and promote health by teaching the community about the benefits of good health. This is in line with what has been postulated by Tashobya \& Ogwal [28] who point out that PHC is a broad concept of health beyond disease and health care but of understanding the wider causes of ill-health such as poverty, illiteracy and poor sanitation. The (District Medical Officer) DMO pointed that PHC provides a solid foundation of a single and unified health system that is effective and sound from the grassroots upwards. Both the DMO and DNO also agreed that PHC has managed to reduce the work load of the district hospital hence reducing the number hospitalized patients. In light of this, most of the community members hail PHC for bringing treatment closer to home, as they no longer have to travel 
Sharon R.T. Muzvidziwa-Chilunjika, Alouis Chilunjika.

Dynamics surrounding the Implementation of the Primary Health Care Approach in Zimbabwe's Rural Areas: The Case of Mt Darwin District.

International Journal of Clinical Inventions and Medical Sciences, vol. 3, no. 1, pp. 1-17, March 2021. DOI: 10.36079/lamintang.ijcims-0301.162

long distances to seek medical health with the longest distance being $20 \mathrm{~km}$ from Binga village to Mutungagore clinic. In showing appreciation to the PHC initiative Respondent A noted that: "Primary Health Care (PHC) yakakosha munharaunda medu takanyanyotarisa sesu madzimai tinoda kugara takaongororwa hutano hwedu nguva dzose" - (PHC is central to us women given the fact that our heath should be checked frequently). This shows that PHC has come in handy in addressing health care issues in the Mt Darwin area.

\subsection{An Assessment of the Performance, Effectiveness and Functioning of PHC Activities}

The performance and effectiveness of Primary Health Care is assessed annually to find out whether there is improvement in terms of dealing with or reducing the health woes of the public. The performance is gauged vis-à-vis the progress made in the implementation of the rudiments and elements of PHC. Performance and effectiveness is assessed from the records of the seven essentials of PHC which act as the yardstick and rules to adhere to.

Accordingly, the performance and effectiveness of Primary Health Care Mt Darwin is assessed using the seven rudiments of Primary Health Care in line with the Alma-Ata declaration, namely [28, 29]:

- Promotion of food supply and proper nutrition

- Adequate supply of safe water and sanitation

- Education about existing health woes and ways of preventing and controlling them

- Maternal and child health care

- Immunization

- Appropriate treatment of common diseases

- The provision of essential drugs.

Primary care nurses and Village Health Workers noted that even though Primary Health Care has got seven elements, it has not been feasible for them to provide all the services equally, as the AlmaAta declaration stipulates due to some problems such as scarcity resources. To buttress this Respondent $\mathrm{C}$ argued that: "Hurumende yedu yeZimbabwe haina mari yakawanda yekuvandudza PHC kuno kuDarwin kwatiri. Dzimwe nguva tinoshaya mishonga, uye tinofamba nzendo refu kuti tiwane kurapwa"- (Our Zimbabwean government does not have enough resources to sponsor the delivery of PHC services to the people. Sometimes, medicinal drugs are in short supply and at the same time we travel long distances to acquire medical attention).

Similarly, the functionality of these PHC rudiments is examined by referring to the figures reflected in Table 1 which provide a clear picture of how Mt Darwin district was performing in terms of health service delivery in the years 2009 to 2012. Table 1 is a summary of the statistical figures of the performance of PHC activities in the years indicated. The statistical numbers reveal whether the implementation of the approach is of paramount importance in Mt Darwin in particular and Zimbabwean rural areas in general.

Table 1. Performance of Primary Health Care 2009-2012 in Percentages

\begin{tabular}{lcccc}
\hline \multirow{2}{*}{ PHC Elements and Indicators } & \multicolumn{4}{c}{ Year } \\
\cline { 2 - 5 } & $\mathbf{2 0 0 9}$ & $\mathbf{2 0 1 0}$ & $\mathbf{2 0 1 1}$ & $\mathbf{2 0 1 2}$ \\
\hline Education & - & - & - & - \\
\hline Promotion of nutrition & 56 & 60 & 67.6 & 70.5 \\
\hline Sanitation & 32 & 40 & 43 & 45 \\
\hline Maternal and child care & 55 & 67 & 66.8 & 69 \\
\hline Immunization & 65 & 70 & 73 & 75 \\
\hline Treatment of common diseases & 54 & 60.4 & 50 & 63 \\
\hline Provision of essential drugs & 40 & 57 & 50 & 39 \\
\hline Source: & & & &
\end{tabular}

Source:

Underlying data, statistical records (2009-2012) Mt Darwin District Hospital

Table 1 shows the performance of PHC from 2009 to 2012 at Mt Darwin District Hospital. This performance was actually gauged in relation to the several PHC elements and indicators. In line with 
this it can be argued that as PHC is being implemented, In terms of education the Table above shows that there was no statistics collected from 2009 to 2012. In relation to the PHC dimension of promotion of nutrition, in 2009 it recorded $56 \%$, then in 2010 there was a steady increase to $60 \%$, then in 2011 there was a also an increase to $67.6 \%$ then in 2012 PHC's efforts towards the promotion of nutrition registered $70.5 \%$. In terms of sanitation, in 2009 it recorded $32 \%$, then in 2010 it was at $40 \%$, then $43 \%$ in 2011 and lastly $45 \%$ in 2012. PHC has also played a crucial role in the area of maternal and child care as witnessed by the statistics where in 2009 it recorded $55 \%, 67 \%$ for 2010 , with $66.7 \%$ in 2011 and 2012 having $69 \%$. Then for immunization, 2009 recorded $65 \%$, whilst $70 \%$ was recorded for the year 2010, 73\% and 75\% were recorded for the years 2011 and 2012 respectively.

Treatment of common diseases recorded $54 \%$ in 2009 , while 2010 it was $60.4 \%, 2011$ recorded $50 \%$ and in $201263 \%$ was recorded. Lastly, on the provision of essential drugs in 2009 it recorded $40 \%$, whilst 2010 recorded $57 \%$, then 2011 recorded $50 \%$ and 2012 it recorded $39 \%$ a significantly low rate. Over and above, it can thus be argued that PHC has been instrumental in promoting nutrition, sanitation, maternal and child care, immunization, treatment of common diseases and provision of essential drugs. In this vein, it can be argued that PHC as a multi-dimensional health care initiative has been performing well in regards to those elements and the year 2012 has generally seen the statistics across board being on the high, thus signifying some remarkable progress in the implementation thereof. The increase in the 2012 statistics also bears testimony to the rate of acceptance and support of the PHC initiatives in Mt Darwin.

\subsubsection{The Importance of Health Education on Prevailing Health Problems in Mt Darwin}

Education about prevailing diseases is a functional area in the PHC programme of Mt Darwin although the statistics were not available for compilation because the District Health Education Officer (DHEO) was on manpower development leave from 2009-2012, and no one was in office to supervise and monitor the programmes on her behalf as she works alone in the district. This is a cause of concern as it results in poor service delivery and inefficiency in the department. The DMO highlighted that Village Health Workers are very useful as they have managed to equip the people in their communities with knowledge to reduce resistance to prevailing sicknesses such as Malaria and diarrhoea that could infect and affect them badly. Sensitization meetings are done in primary care centres targeting community leaders such as headmen and church leaders and the agenda differs from time to time depending on new developments in relation to preventions. For example, when Rota Vaccine was introduced in 2013 as the new drug for treating diarrhoea in infants.

The DMO further stated that Village Health Workers are also vital tools in mobilizing the community to attend and participate in health education campaigns and commemorations that are held at district level which include World AIDS Day, World TB Day and Malaria Day. Community participation has witnessed tremendous increase and improvement in diseases prevention and control as they would have acquired information required in regard to what to do and what not to do for example, most mothers can now prepare the salt and sugar solution to cure diarrhoea. However, there are problems in relation to this aspect as highlighted by the DMO and Village Health Workers who stated that most people still do not attend public meetings in great numbers to get health education, which is given free of charge. This might be attributed to the fact that they do not attach much value to these campaigns as they regard them to be of less value since there are no tangible benefits attached thereto.

Moreover, most of the campaigns are donor funded and most times the funds come late or never come hence undermining the success of this element of PHC. Moreover, inadequate funds result in the production of few Information Education Communication (IEC) materials such as t-shirts, pamphlets, banners and posters which are used communicate important information to the public after and before campaigns and commemorations. Murisa [21] points out that as a result of the serious scarcity and disruption of transport and telecommunications, several programmes including patient transfers, malaria indoor residual spraying, drug distribution and management of districts and rural health centres have been compromised. Moreover, from observations done by the researcher some community members still to not take heed to the health education they receive as most farmers prefer to build tobacco bans with asbestos and bricks whilst they live in huts made of poles and mud meaning they are still unconscious of their own health. 
Sharon R.T. Muzvidziwa-Chilunjika, Alouis Chilunjika.

Dynamics surrounding the Implementation of the Primary Health Care Approach in Zimbabwe's Rural Areas: The Case of Mt Darwin District.

International Journal of Clinical Inventions and Medical Sciences, vol. 3, no. 1, pp. 1-17, March 2021. DOI: 10.36079/lamintang.ijcims-0301.162

\subsubsection{The performance of the Promotion of Nutrition Element in Mt Darwin}

It can be concluded that promotion of nutrition is functioning well in Mt Darwin. The district's nutrition unit has divided its activities into four programmes that are [31,32]:

- Growth Monitoring

- Maternal and Child Nutrition

- Community Management of Acute Malnutrition (CMAM)

- Outpatient Therapeutic Programme

Out of these four, two (growth monitoring and CMAM) depend on the PHC approach to be successful. The Growth Monitoring programe is implemented through community based growth monitoring and clinic based growth monitoring. Community based growth monitoring is done by VHWs who have been capacitated through various trainings that have been conducted in their various wards. In order for the programme to be effective, every Village Health Worker is to be given Salter balances (for weighing infants). In this regard, only 24 of these were distributed in 2010 and a number of them have being reported not functioning since they lack repairs. This antagonizes the full implementation of the PHC approach in Mt Darwin. Table 2 provides a summary of the annual totals of the children who took part in growth monitoring in the years 2009-2012.

Table 2. Summary of Children Weighed

\begin{tabular}{ccc}
\hline Year & No of children weighed & No of children below the line \\
\hline 2009 & - & - \\
\hline 2010 & 5391 & 186 \\
\hline 2011 & 4100 & 200 \\
\hline 2012 & 3959 & 209 \\
\hline
\end{tabular}

\section{Source:}

Master Card Summary 2009-2012 Mt Darwin district hospital

Table 2 clearly shows a summary of children weighed as well as those who were under-weight. The year 2010 saw 5391 children being weighed in the Mt Darwin district, and of those who were weighed, 186 were found to be under-weight. In 2011 a total of 4100 children were weighed at the Mt Darwin District Hospital and 200 children were found to be underweight. In 2012, 3959 children were in the same vein weighed and 209 were found to be underweight. In light of this, years 2010 and 2011 were the most successful years compared to other years. This was attributed to successful National Immunization Days (NIDs) and Child Immunization Days (CHDs) which were well funded by UNICEF.

Moreover, this shows proper community participation in matters relating to their health. The reduction of the number of children brought to be weighed year by year can be attributed to a number of factors which include lack of resources such as Salter scales and transportation to transport health workers to various points to weigh infants. It can also be a result of family planning methods made available to mothers as statistical reviews from clinics show that the rate of unplanned pregnancies has been reduced. However, most Village Health Workers were not pleased with the performance of this programme during the rainy season with one of them (Respondent B) complaining that: Most mothers are not serious about the health of their children especially during the rainy season; they prefer their fields than coming to have their babies weighed. Sometimes they send small children with their babies and this becomes difficult for us as some of the infants will be ill and in need of special attention.

CMAM was introduced in 2010 and has been functioning averagely since then. This programe was introduced to eradicate malnutrition in rural areas like Mt Darwin characterised by food insecurity. According to Primary Care Nurses who were interviewed; the high numbers of malnutrition cases are also a result of poor quality of complementary food given to children, and also early weaning which has resulted in Kwashiorkor. A formula called Ready to Use Therapeutic Food ( RUTF) or "plump nut" which is donated by UNCIEF is been used to manage acute malnutrition to those children indentified by VHWS during growth monitoring and are referred to the district hospital for 
rehabilitation. According to UNICIEF guidelines the Cure rate sphere standard is $75 \%$, Death rate $<10 \%$ and Defaulter rate $<15 \%$. The bar graph below provides a pictorial view of the statistical performance of the programe. The success of the programe in 2011 is credited to proper management and supervision of VHWs and other health workers by the District Nutritionist as he conducted workshops and trainings on Nutrition Point Person Training and Contemporary Nutrition and Child Care Practices where 24 VHWs were trained.

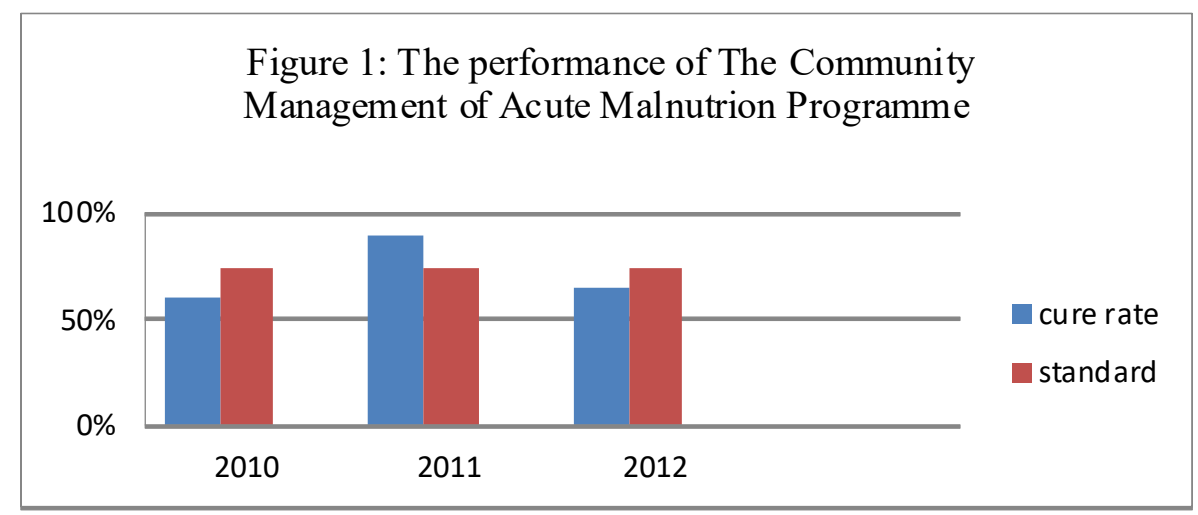

Source:

Statistical Records (2010-2012) Department of Nutrition Mt Darwin District Hospital

Figure 1. The Performance of the Community Management of Acute Malnutrition Programme

From Figure 1, it can be observed that the years 2010 and 2012 were not very successful due to lack of adequate RUTF supplies as at times it can take up six months to get the supply leading to the increase in the defaulter rate. The DMO articulated that malnutrition in Mt Darwin will remain a challenge as long as the community continues in poor food production as many have resorted to tobacco farming. One community member (Respondent D) pointed out succinctly that "beans, wheat and maize do not pay us when well sell them and therefore it is a waste of time growing them." However, Murisa [21] argued that the Department of Nutrition in the Ministry of Health and Child Welfare has never gained status compared to other departments in the same Ministry. It has remained undersized with limited staff, finances and outreach capacity. As a result, nutrition promotion activities have remained marginalized hence the current institutional setup in the country should effectively promote human nutritional issues.

\subsubsection{The Importance of Maternal and Child Care Services in Mt Darwin}

The Primary Health Care programme in Mt Darwin offers maternal and infant health care services including family planning and care of high risk groups. It has been emphasized that maternal and child care is one of the most effective and fruitful service in the district, especially because the Mt Darwin PHC was first introduced with this feature due to the woes of maternal and child mortality which were severe. The programme has been perceived as successful as the health of mothers and their babies has improved remarkably with approximately 63.2 (mean) success record from 20092012, as against $28 \%$ in 2007-2008. Statistical reviews from clinics show that the rate of haphazard bearing of children as well as unnecessary pregnancies have been reduced as family planning services are now accessible to most women in different parts of the district.

However, irregular attendance to the clinics by mothers poses threats to the success of the programme as most of them do not show up at health centers on specific dates for frequent check-ups which in turn leads to poor health. Despite the removal of user fees in rural areas by the government there were numerous complaints from the VHWs in Tsakare about one elderly woman from the apostolic sect delivering women at home. In this vein, hospital records reveal that in December 2012, 14 women died from such unhealthy practices despite police interventions to stop her. Similarly, a report by the Portfolio Committee on Health and Child Welfare in 2010 [34] indicated that many Zimbabwean women are opting to give birth at home despite the obvious dangers hence undermining 
Sharon R.T. Muzvidziwa-Chilunjika, Alouis Chilunjika.

Dynamics surrounding the Implementation of the Primary Health Care Approach in Zimbabwe's Rural Areas: The Case of Mt Darwin District.

International Journal of Clinical Inventions and Medical Sciences, vol. 3, no. 1, pp. 1-17, March 2021. DOI: 10.36079/lamintang.ijcims-0301.162

government efforts to eradicate maternal mortality. Such challenges pose problems to the success of this aspect of the PHC approach in the area.

\subsubsection{The benefits of Immunization to Children and Women in Mt Darwin}

Immunization against the major infectious diseases is also very functional in Mt Darwin. The Immunization Programme is implemented under the Zimbabwe's Expanded Programme on Immunization (EPI). To this effect, the district has set up a permanent EPI team which moves around the district every month immunizing children and this has reduced the burden on both health workers and the community as they do not have to wait long lines to be served and also overwork themselves by serving many patients a day. One mother claimed (Respondent D) "a child immunized against the seven child killer diseases is protected for life." Thus showing that the people in the community have relatively embraced the immunization programme. Mothers also benefit from immunization as they are dosed with tetanus toxoid during pregnancy to protect themselves and their unborn babies from tetanus.

The researcher however observed that husbands are not supportive of their wives as most of them are not actively involved in health issues, for example, bringing their babies to be immunized, weighed and also to review appointments during pregnancy. One nurse indicated "we have some women who keep their hospital cards at the clinic because they are afraid of their husbands knowing they are visiting the clinic, especially those of the apostolic sect who are not allowed to visit the hospital." Such behaviour by males undermines proper use of hospital services by females leading to poor child and female health.

\subsubsection{Sanitation Woes and Provision of Safe Water in Mt Darwin}

The provision of suitable sanitation and safe water services to a community is a basic right. Sanitation in Mt Darwin is still a huge challenge; many households in villages like Musoki, Nowedza and Madzikana are still lacking proper sanitation and safe water. According to records compiled by a VHW in Nowedza, one village Nowedza 1A with a population of 200 has two standard toilets, that is, the ventilated improved pit-toilet. Another village Madzikana 3C with a population of 150 has no toilet buildings meaning they are still using bushes as toilets. VHWs and the communities in these areas are concerned with the frequent diarrheoral outbreaks that occur as a result of poor water and sanitation services. Villagers in these areas pointed out that they have no money to build toilets as they have no access to the hard currency used in the country and were wishing for the government to come to their rescue. However, as noted by the Alma-Ata Declaration [27], taking consideration of the financial state of the government of Zimbabwe this might not be possible and therefore the community should make efforts on their own to build toilets with the little they have whereby promoting a spirit of self-reliance.

In most villages mentioned above there are also no clean water sources and some of the villagers depend on water curing tablets to treat the water they drink. However sometimes they fail to access these tablets as they are sold or as they will be out of stock since they are donated. A small percentage of the community members interviewed noted that the water tablets brought with them a funny smell and preferred not to use them meaning they use untreated water.

\subsubsection{Provision of Essential Drugs and Treatment of Common Diseases in Mt Darwin}

The Primary Health Care programme in Mt Darwin also provides essential drugs required to treat illness to better the lives of the residents in the area. The provision of essential drugs and the subsequent treatment of common diseases at the Mt Darwin District Hospital has not been running smoothly, due to a number of factors which include drug shortages, delays by the government to deliver drugs, delays by the district to attend to proposals and reports from clinics and Village Health Workers. The DNO and DMO highlighted that there is a huge challenge of drugs that expire in large quantities due to lack of proper facilities to store them, especially those that require specific conditions and temperatures. This is a result of shortages of refrigeration facilities and power cuts that are intense in rural areas. Despite attempts to use gas refrigerators to help store the drugs money to purchase the gas is still a challenge.

It is also alleged that some drugs are being sold illegally by nurses at both clinical and district level and this has contributed to the poor functionality of drug distribution. Respondent $\mathrm{C}$ averred that tinozviziva kuti manurse arikuba mapiritsi nemishonga ndosaka tirikuishaiwa kuchipatara (we are 
aware that the nurses are stealing drugs and medication from the hospital that is why there are consistent shortages of drugs). Although this has not been confirmed to be true it has negatively affected the reputation and credibility of the nurses in the district. Additionally, this has also raised issues of governance in the use of resources and has made donors unwilling to fund PHC activities. Treatment of common diseases in Mt Darwin performs averagely as most local common diseases like Malaria and Diarrhoea are treated and controlled with the drugs available. Most people in the area have grown to accept that living a healthy life is one's responsibility and therefore they now know where to go to seek medical help. Without adequate drugs and personnel there is no proper implementation of the PHC approach and therefore it means poor health service delivery.

\subsection{Challenges Encountered in Implementing PHC in Mt Darwin}

The study established that financial, material and human resources are limited in many developing countries like Zimbabwe hence it is constantly a challenge to implement demanding programmes as the PHC approach. According to the DHO implementing PHC initiatives is at stake in Zimbabwe's rural areas. The Mt Darwin district is equally affected by the lack of the human, material and financial resources, thus making it difficult for PHC initiatives to fully and successfully operationalise. PHC requires that resources be available whenever they are needed so that health care services can be given to the public effectively and efficiently. In this vein, the study established that there are no adequate resources to effectively execute the approach hence some of its elements such as sanitation are poorly functioning in rural areas.

In supporting the above notion in a more specific way, a number of challenges were highlighted by VHWs in relation to their working conditions. The most common challenge is that of salaries. Although they admit that their job is voluntary, they still find it unfair that the Government does not honour its promises to give them some allowances three times a year. One female Village Health Worker explained, "Last year I ended up buying maize to cook for my family after I had produced a little in my field due to endless workshops I attended during the rainy season that did not even pay me." The VHWs indicated that sometimes the workload is burdensome that on average they serve up to 10 people a day and sometimes they attend to some patients in the village during the night.

Additionally, there is lack of essential equipment and medical instruments. The District Nursing Officer revealed that a kit of 29 items that should be provided to the VHWs is not coming in time from the Government and when they do they are inadequate, hence making it difficult for VHWs to execute their duties well. The VHWs stated that they sometimes end up using personal resources such as candles incase patients come during the night, stationery to write reports that are submitted to the clinics twice a month and airtime to communicate with nurses at clinics in case of emergence. According to most of them such conditions makes their work unbearable.

The research findings gathered reveal that PHC is an essential means of delivery quality health services in rural areas and for this to take place the government, community and different stakeholders should co-ordinate in the implementation of the PHC approach in Zimbabwe's rural areas in general and Mt Darwin in particular. However the Government of Zimbabwe is still facing difficulties in funding the approach and this result in poor implementation of PHC.

\section{Conclusions and Recommendations}

\subsection{Conclusions}

The findings of the study were mainly anchored on face to face interviews, observations and documentary evidence as data collection methods. The literature reviewed pointed out that PHC is an effective tool for delivering health care that is easily available, accessible, acceptable and affordable maintained through community participation and multisectoral collaboration. In as much as PHC has been an important mechanism for health service delivery in Zimbabwe there are still challenges constraining the full implementation of the approach.

The study concluded that PHC plays an important role in decentralizing health care services as it is intended to ensure health care coverage at community level through the participation of people in improving their day-to-day health living. The study concluded that PHC has significantly improved health service delivery in Zimbabwe. The statistics from Mt Darwin Hospital on different PHC elements shows that the approach is functioning well to date and has done a great deal in reducing health related woes in the area which include high incidence of Malaria and HIV and AIDS, high maternal and child mortality and severe malnutrition. The performance of services offered at primary 
health care centres in relation to other health service delivery mechanisms at secondary, tertiary and quaternary centres proves that PHC is a worthwhile intervention as it promotes social justice. It is largely acknowledged by national and global health planners that community participation is the answer to the successful implementation of primary health care. The contributions by the public in defining problems and planning matters to do with their health makes them feel accountable, not only for their own health, but also that of others thus improving the standards of their lives. It is therefore clear that without the people there would be no PHC and without PHC, societies will face health problems.

In relation to the assessment of the performance, effectiveness and functioning of PHC activities, the study assessed the seven rudiments of PHC in line with the Alma Ata declaration namely [27]: promotion of food supply and proper nutrition, adequate supply of safe water and sanitation, education about existing health woes and ways of preventing and controlling them, maternal and child care, immunization, appropriate treatment of common diseases and the provision of essential drugs. The study concluded that education about prevailing diseases is a functional area in the PHC programme of Mt Darwin as they have meaningfully equipped the people in their communities with the knowledge to reduce resistance prevailing sicknesses. However, there are problems associated with the inconsistent participation and attendance of most villagers in public meetings to get health education.

In addition, the study also looked at the second rudiment of PHC in Mt Darwin which is the performance of the promotion of the nutrition element where it concluded that promotion of nutrition is functioning well in Mt Darwin. However, the Department of Nutrition within the Ministry of Health has remained undersized with limited staff, finances and outreach capacity, thus making it difficult to fully undertake and implement nutrition promotion activities. In relation to the maternal and health care services in Mt Darwin, the study concluded that this rudiment is the most effective and fruitful service as the PHC in Mt Darwin offers maternal and infant health care services including family planning and care of high risk groups.

The immunization to children and women rudiment proved to be very functional in Mt Darwin as the programme is being implemented under Zimbabwe's Expanded Programme on Immunisation. In relation to the provision of sanitation and clean water rudiment, the study concluded that this area is still a huge challenge as many households (e.g. Madzikana, Nowedza, Musoki etc.) are still lacking proper sanitation and safe water. Lastly, the rudiments of provision of essential drugs and treatment of common diseases in Mt Darwin the study concluded there is lack of consistent and uninterrupted flow of drugs as there is drug shortages, delays by the Government in the delivery of drugs as well as delays by the district to attend to proposals and reports from clinics and VHWs.

The study also explored the challenges that militate against PHC is Mt Darwin. The study concluded that there is the lack of resources that has undermined the proper implementation of PHC in Mt Darwin. The study concluded that the implementation and operationalization of the PHC programme was greatly affected by the lack of resources that is material, financial and human resources to initiate and support the PHC programme. The Government of Zimbabwe has not been faithful in honoring their promise to give the VHWs their allowances. This therefore demotivates the VHWs who are the key drivers of the PHC programme. This therefore compounds the problem of shortage of staff. Lastly, there is lack of essential equipment and medical instruments for the VHWs to undertake their tasks thus making it difficult to offer PHC facilities in Mt Darwin.

\subsection{Recommendations}

The study made the following recommendations in a bid to strengthen and enhance the implementation of PHC in Mt Darwin:

1. Enhancement of community participation in health care

There is need to promote maximum community participation in planning, operating and organizing primary health care systems to foster accountability and transparency. Moreover because the community seeks for health services that meet their needs and expectations.

2. Mobilisation of sufficient resources

There must be efforts by the Government to mobilise funds from the donor community to refurbish PHC centers with new and improved equipment, drugs and infrastructure as most centres in Mt Darwin have outdated ones. Moreover the aid should be channeled towards 
salaries for the VHWs who go for months without payment. Funds should also be channeled towards trainings and workshops for the VHWs in order to keep them up with the changing times.

3. Encourage multi-sectoral collaboration

There is need for multi-sectoral collaboration. All interrelated sectors and aspects of national and society development; in particular agriculture, animal husbandry, industry, education, housing, public works, communications and ought to be harmonized in the implementation of the PHC approach. In line with this, there must be public policy reforms that secure healthier communities by integrating all sectors such as agriculture, industry and education with PHC goals. Doing this will ensure universal coverage and improved service delivery. It is known that PHC initiatives seek to improve the health of populations at a local level, however if national and global policy makers align policies with PHC goals the benefits will be felt at both national and global levels. Again multi sectoral collaboration will result in "whole-of government approach" where all sectors will contribute to solving health problems.

4. Enhance Affordability of PHC

Peters et al. [19] states that it is the relationship linking the cost of services (in part affected by their costs) and the willingness and ability of the public to pay for those services, as well as be protected from the financial consequences of health expenses. Accordingly, Abdulrahem et al. [20] asserts that most rural populace have money at harvest time; they are poorest and sickest in the months before the harvest, which is when they may not be able to buy medicines, this becomes problematic in the event that one falls ill and is not able to access health care as most of these rural people will see no need of spending their last cent in health care. As noted by the Zimbabwe Health System Assessment (ZHSA) [30] dollarization in Zimbabwe has also negatively impacted over 60 percent of patients especially those in the rural areas as they are unable to pay user fees that hospitals are allowed to charge. This therefore calls for strategies such as yearly payment after the harvest, so that communities buy key medicines in bulk which will sustain them till the next harvest. However such strategies may not work if people do not trust their health personnel hence there is need for good relationships between the community and the health workers.

5. Improved availability of PHC facilities

Availability as postulated by Peters et al. [19] entails getting the exact kind of care accessible to those who are in need, such as hours of operation and waiting periods that meet demands of patients, as well as having the suitable type of service providers and resources. World Health Organization refers availability as the physical presence of the delivery of services, compassing health infrastructure, core health personnel, and service utilization. In this regard World Health Organization Report notes that health systems are facing problems due to lack of resources to deal with increasing public expectations and technological developments. The availability of resources such as skilled personnel and appropriate technology will help primary care systems keep abreast with the dynamic environment and emerging diseases. This may include increasing the number of physicians that are trained, improving workplace systems and increasing the efficiency of care without compromising the quality.

6. There is need to improve the acceptability of PHC

According to Peters et al. [19], acceptability is the match between how responsive health service givers are to the social and cultural expectations of individual users and communities. It should be noted that for PHC to be successful in rural areas, people should be educated so as to be enlightened from traditional conservatism and resistance to ideas from outside. Most rural dwellers are illiterate thus modern ways of doing things are not appreciated to them; this includes modern ways of health service delivery, for example, a man being sent to a clinic for sexually transmitted disease and to be treated by a female worker. When introducing any new technology, Hegazy et al. [24] argued that the society, especially in rural areas, must be assured that it will not contravene the beliefs and practices of local culture. Also for PHC to be acceptable in rural areas community leaders 
Sharon R.T. Muzvidziwa-Chilunjika, Alouis Chilunjika.

Dynamics surrounding the Implementation of the Primary Health Care Approach in Zimbabwe's Rural Areas: The Case of Mt Darwin District.

International Journal of Clinical Inventions and Medical Sciences, vol. 3, no. 1, pp. 1-17, March 2021. DOI: 10.36079/lamintang.ijcims-0301.162

should be incorporated in the systems as they have great influence on how their people participate in activities that need them.

\subsection{Overall}

Around the globe, PHC is considered as the main aspect that is fundamental for population health, WHO even declared "health for all" its ultimate goal. Primary Health Care is a vital tool in as far as health service delivery is concerned in rural areas. It seeks to promote equality, equity and quality in the distribution of health services at a cost that the community can afford. Moreover, it decentralizes health services bringing them closer to the people through their involvement and participation. However, lack of resources in the face of material, human resources and financial have hindered the effective implementation of the approach in rural areas such as Mt Darwin. Over and above, the study concludes that no sector involved in socio-economic development, especially the health sector, can function well in seclusion hence partnerships are needed to improve health service delivery. This means that all interrelated sectors and aspects of national and society development; in particular agriculture, animal husbandry, industry, education, housing, public works, communications and ought to be harmonized in the implementation of the PHC approach. The Government should therefore come up with mechanisms to fund the approach in order redress the health inequalities posed by health systems.

\section{References}

[1] A. L. Hixon, and G. G. Maskarine, "The Declaration of Alma-Ata on its 30th Anniversary: Relevance for Family Medicine Today," FAM Med, vol. 4, no. 8, pp. 585-8, 2008.

[2] Alma-Ata Declaration, Primary Health Care, World Health Organization. Geneva, 1978.

[3] D. Sanders, "Equity in Health: Zimbabwe Nine Years On", Journal of Social Development in Africa, vol. 5, no. 1, pp. 5-22, 1990.

[4] J. M. Kazembe, The women issue, in Mandaza Ibbo (Ed), Zimbabwe: The Political Economy of Transition, 1980-1987. Dakar: University Press, 1986.

[5] R. Sunanda, and N. Masuka, "Facilitators and Barriers to Effective Primary Health Care in Zimbabwe," African Journal of Primary Health Care and Family Medicine, vol. 9, no. 1, pp. 23-45, 2017.

[6] A. Mlambo, and B. Raftopoulos, "The Regional Dimension of Multi Layered Crisis: An Analysis," 14 June 2009. [Online]. Available: www.iese.ac.mz/lib/publication/proelit/AloisMlambo.pdf. [Accessed: September 2020].

[7] World Bank World, "World Development Indicators," July 2005. [Online]. Available: http://www.worldbank.org, 2005. [Accessed: September 2020].

[8] G. Kanyenze, "The Outlook for the Zimbabwean Economy," Harare: Supporting Economic Transformation, 2017.

[9] S. Shoultz, and D. Hatcher, "A Critical Practitioner for Every Person in the World," Health Policy Developments, vol. 3, no. 4, pp. 34-68, 1997.

[10] Institute of Medicine, National Strategy to Reduce Social Inequalities in Health. Oslo: Govt Press, 1994.

[11] World Health Organization, World Health Organization Report. United Nations: New York, 1978.

[12] World Health Organization, World Health Organization Report, Primary Health Care, Now More than Ever. United Nations: New York, 2008.

[13] R. MacLean, A. S. Tarlier, and F. Steward, "No cookie-cutter response, Conceptualizing Primary Health Care, Tutor-PHC 2003/2004," Reseach Trainees. Vancouver: University of British Columbia, 2004.

[14] M. Mona, "Key Elements of Primary Health Care," June 2016. [Online]. Available: www.nursingexercise.com. [Accessed: September 2020].

[15] R. Loewenson, The political economy of health and nutrition. London: McMillan, 1998.

[16] Ministry of Health and Child Care. "The National Health Strategy for Zimbabwe 2016-2020," May 2016. [Online]. Available: http://www.zimgov.co.zw. [Accessed: October 2020].

[17] Zimbabwe Statistics. "Population Census," May 2012. [Online]. Available: http://www. zimstats.co.zw. [Accessed: September 2020]. 
[18] Zimbabwe Health Matters. "Primary Health Care Strategy in Zimbabwe," July 2012. [Online]. Available: http://www.zimgov.co.zw/Ministry of Health and Child Welfare. [Accessed: November 2020].

[19] D. H. Peters, A. Gary, G. Bloom, D. G. Walker, W. R. Brieger, and M. H. Rahman, Poverty and Access to Health Care in Developing Countries. New York: Ann Publishers, 2008.

[20] I. Abdulrahem, A. R. Olapipo and M. O. Almodu, "Primary Health Care Services in Nigeria: Critical Issues and Strategies for Enhancing the Use by the Rural Communities," Journal of Public Health and Epidemiology, vol. 4, no. 2, pp. 38-52, 2012.

[21] T. Murisa, Social Development in Zimbabwe, Discussion Paper Prepared For the Development Foundation for Zimbabwe. Harare: DFZ, 2010.

[22] E. E. Obioha, and M. G. Molale, "Functioning and Challenges of Primary Health Care Program in Roma Valley," Lesotho. Ethon Med, vol. 5, no. 2, pp. 135-56, 2011.

[23] E. Mike, "Community Participation in PHC services in Nigeria," February 2010. [Online]. Available: www.ngnhc.org/. [Accessed: September 2020].

[24] I. S. Hegazy, M. S. Ferwana, and N. A. Qureshi, "Utilization of Maternal Health Services of Comparative Study between Residents and Nomads," Saudi Medical Journal. vol. 7, no. 2, pp. 45-68, 1992.

[25] D. Howitt, and D. Cramer, Social Science Research: Techniques and Applications. New York: Longman, 2005.

[26] J. Castillo, Sampling Techniques Revised. Oxford: Oxford University Press, 2009.

[27] Alma-Ata, Declaration of Alma-Ata International Conference on Primary Health Care. USSR, 1978.

[28] C. K. Toshobya, and P. O. Ogwal, "Primary Health Care and Health Sector Reforms in Uganda," Health Policy and Development Journal. vol. 2, no. 1, pp. 45-67, 2002.

[29] APNA. "Supporting Nurses in Primary Health Care," May 2012. [Online]. Available: www.apna.asn.au. [Accessed: November 2020].

[30] Zimbabwe Health System Assessment, "Health Barometer," August 2010. [Online]. Available: www.healthsyte ms2020. [Accessed: November 2020].

[31] Reuters, "Primary Health Care Reforms in Sub Saharan Africa," October 2010. [Online]. Available: www.reuters.org. [Accessed: September 2020].

[32] Government of Zimbabwe National Health Strategy for Zimbabwe, "Health Strategy 20092013," March 2009. [Online]. Available: http://mhcw.gov/ Ministry of Health and Child Welfare/. [Accessed: September 2020].

[33] Government of Zimbabwe, "National Health Account 2015 in Zimbabwe," July 2015. [Online]. Available: http://www.zimgov.org. [Accessed: July 2020].

[34] P. Barros, and J. Simoes, "Portugal: Health System Review. Geneva WHO Regional Office for Europe on Behalf of the European Observatory of Health Systems and Polices," June 2008. [Online]. Available: http://www.euro.who.int/Document/E90670pdf. [Accessed: November 2020]. 